\title{
An Energy Efficient Architecture for loT Based Automated Smart Micro-Grid
}

\author{
Zeeshan ALI KHAN, Ubaid ABBASI
}

\begin{abstract}
The concept of smart grid is getting more and more attention for efficient energy generation and distribution. There is a need to reduce the energy consumption by efficiently utilizing the resources. Smart gird originates the research in a number of associated applications. These include energy consumption, minimization, database efficiency and efficient communication infrastructure. In this article, we proposed architecture for optimizing the usage of energy resources by effectively utilizing the Renewable Energy (RE) resources. The proposed architecture utilizes Internet of Things paradigms for collecting the power consumption profile of heterogeneous devices. Based on obtained information, a schedule is generated and distributed by the Micro-Grid for certain devices. The analysis shows the efficiency of proposed architecture by reducing the cost of electricity purchased from the external sources. Finally, the realization of proposed architecture for various robotics applications is explained.
\end{abstract}

Keywords: Energy Management; Internet-of-Things; Renewable Energy; Smart Micro Grid

\section{INTRODUCTION}

Due to the scarcity of fossil fuel, the future of technology advancements and research depends on the usage of cleaner energy sources and better utilization of energy. In order to achieve this goal, government agencies are working on development of a new energy infrastructure known as "The Smart Grid". The purpose of smart grid is to effectively manage the processes of energy transmission, generation and distribution. All the stakeholders including the distributors, consumers and producers are allowed to have a two-way communication to produce, consume and distribute the energy in an efficient manner. The biggest energy consumers are buildings such as houses, structures and offices and in developed countries the buildings consume $37 \%$ of energy. While, $28 \%$ of energy is consumed by industrial sector and $32 \%$ energy is consumed in transportation sector [1]. The percentage is even higher in the under developed countries due to the lack of industrial sector. Therefore, energy efficiency can be achieved by efficiently using the available energy sources. The objective can be realized if the energy usage is known in time. This information has to be transmitted to the local smart grid to achieve the goal of energy minimization. Furthermore, the energy could be conserved if the heavy duty devices are scheduled in an automated and efficient way. Another option is to use the RE sources such as solar cells and wind turbines that reduce the dependency on the power supply from energy companies. Moreover, [2] has declared energy conservation as the most important fuel in energy generation. The problem of anticipating and responding to the variable energy demand becomes extremely complicated due to the addition of renewable energy sources such as wind and sun.

In this article, we proposed energy efficient architecture to optimize the energy and its cost. The proposed architecture considered different energy resources and then performed the optimization decision on the basis of feedback received from different components. Our proposed architecture is based on the concept of selfmanaging energy system. The priorities and constraints of consumers will be transmitted to the self-managing energy system (SES). The energy usage will be optimized by the SES using this information, along with the power demand and supply prediction. The SES will also be able to integrate renewable energy such as solar energy, wind energy into the system. The energy consumption requirements are communicated to the system using Internet of things (IoT) based networks. This IoT network communicates with different devices and provides feedback to micro grid for performing the optimizing decision. The following objectives can be achieved using the proposed architecture:

- To design a localized Internet of Thing (IoT) based network for transmitting and receiving information to/from devices and consumers.

- To automatically control energy consumption of devices using the priorities and constraints set by the consumers.

- To provide feedback to the consumers of their energy usage pattern, in order to achieve energy and cost savings.

- To be able to integrate renewable sources of energy into the system.

Section 2 explains the related work in the fields of energy optimization. Section 3 describes the proposed architecture for smart micro-grid using an Internet of Thing (IoT) network. Moreover, case study for the proposed system in robotics applications is presented in section 4. Finally, section 5 concludes the article.

\section{RELATED WORK}

A number of approaches have been proposed to minimize the energy consumption in Smart Grid networks. Often these problems are formulated as the optimization problems having the objectives such as determining the power flow values while minimizing the cost of the system. In order to determine the optimal smart grid architecture for a certain electricity demand, [3] proposed the renewable energy resources. However, the optimization model is not discussed in detail. The author in [4] focuses on utilizing the potential of domestic technologies so that consumers can participate in the electricity production process. Several linear programming models are developed to find the optimal combination of supply sources and the path through which the power should flow [5]. Although these models seem effective by taking into consideration 
the uncertainties associated with the alternative sources however, they are unable to handle Demand-Response (DR) actions. The concept of renewable energy network with respect to demand, supply and technology is useful to consider for optimal distribution of renewable energy. The authors in [6] proposed a concept that depicts the operation of renewable energy generation and distribution within a municipality by establishing the local virtual energy cooperatives that aim to fulfill energy needs of the community. The concept is demonstrated through an example of biomass network deployed. Few home energy management systems are proposed that consider the customer behavior as well as the presence of distributed generation and storage facilities (batteries, fuel cells etc.) [7]. These models are designed for home use but not extended to the power grid level. Khan et al. [8] discuss the demand side management (DSM) based on genetic algorithms for minimizing the cost of expensive power plants by considering individual users cost. The results show the effectiveness of the proposed scheme for single and multiple user scenarios. The optimization model for Leaf Community micro grid by using the genetic algorithms in Matlab is discussed in [9]. The proposed work predicts the energy production and consumption using neural networks and uses this information to optimize the energy cost and maintenance cost of energy storage system. Ref. [10] discusses the economic scheduling of isolated operation of a small power system and it is concluded that right timing can maximize the supply performance. The considered power sources are wind turbine, solar unit, fuel cell and storage battery. The system is controlled by a central controller that allows optimal generation and load control. A case study has been implemented in Budapest Tech that demonstrates the effectiveness of the method [10].

Automatic lighting control that aims to reduce the overall building energy consumption based on factors such as time of day, occupancy, daylight availability, etc. is discussed in [11]. The technologies used have different input parameters, control method and control algorithm that need to be considered for energy savings. Smart meter technology across various sectors such as commercial, residential and industrial users has been discussed in [12]. In this article, various areas for power quality improvement have been proposed using smart meters. The concept has been verified using an experimental setup. Ref. [13] discusses a review of the optimal load distribution models of a micro-grid in a smart grid environment. The article also describes an optimal load distribution model of microgrid. Ref. [14] discusses action plans for distributed generation and energy efficiency measures to reduce carbon dioxide emissions. The distributed generation of renewable sources and their integration into micro grids is an asset for local authorities that can efficiently manage that energy. A simulation tool HOMER is used to propose an optimal configuration plan of micro grids for Serbia to obtain low cost for reduced carbon dioxide emissions. Furthermore, several important factors that affect the development of renewable energy generation have been described in [15]. A new model, the Renewable Energy Optimization Model (REOM) has been developed to analyze the development of wind power, solar power and biomass power from 2009 to 2020 . The presented results have important implications for long-term energy policy in developing countries. Finally, [16] discusses a multichoice goal programming model that deals with the capacity expansion planning problem of the renewable energy sources. The presented model involves decision making regarding the optimal generation from different plant types, location selection based on demand and other related criteria. It is proposed that different types of plants should be located in appropriate places so that predefined goals concerning the cost can be optimized. Furthermore, the social acceptance of the renewable energy planning problem in Taiwan has been modelled to demonstrate the effectiveness of the proposed model. In this article, we move a step ahead by not only optimizing energy and cost but also providing an automatic feedback mechanism using an IoT based network.

\section{SMART GRID ARCHITECTURE}

A reliable electrical power system is an important factor for speeding up economic activity in a society. If a number of distributed renewable sources are connected to a power grid, then the traditional power system is not supposed to work efficiently. This is so because the central grid is not aware of the availability of distributed generation sources in the network, hence, it will not be able to optimize the power generation. On the contrary, in a smart grid system, there is a communication facility between renewable generating sources, consumer and central grid, for the exchange of vital information. The smart grid system senses vital information using sensors and actuators, which are installed in a distributed manner. This information is transmitted to the centralized smart grid, for effective management of the power grid network. One of the main features of the smart grid is to seamlessly integrate these renewable energy sources. Hence, a smart grid gathers data related to the generation, transmission and distribution of power. Then it takes necessary measures for efficiently balancing the demand and supply of the generated power [17]. Fig. 1 shows the main component of a proposed architecture for smart grid energy system. The Micro-Grid that is a type of smart grid is the central module, which is responsible for taking the optimization decision, storage of energy and storage of data using the IoT system. There are different energy sources that are available to the Micro grid. The availability and the optimized utilization of these resources is discussed below in detail.

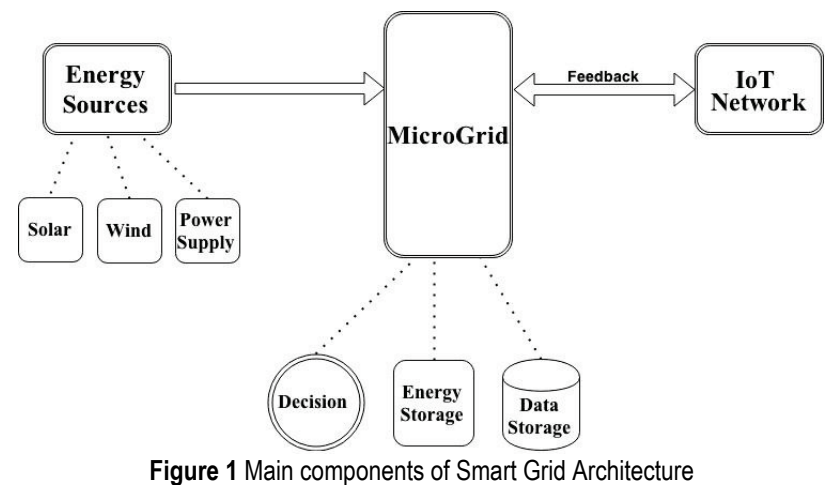

Figure 1 Main components of Smart Grid Architecture 
The reliable and efficient communications system is required for the robust, affordable and secure supply of power through Smart Grids. The IoT enabled network provides the continuous feedback to the Micro-Grid regarding the consumption of energy. IoT can provide a common middleware for smart grid. In this case, the IoT can acquire information from different heterogeneous devices. This information is stored and processed in a uniform way using the Cloud system. The Cloud can provide and support the ubiquitous connectivity for realtime applications [18]. Computational requirements for Smart Grid applications can be met by utilizing the Cloud Computing model. The IoT enabled network is explained in detail in the next sub-section.

\section{1 loT Enabled Network}

The emergence of IoT and its coupling with smart grid makes a dynamic and complex system of energy production and consumption. This system exchanges the information using the communication technologies for attaining the efficiency as compared to its current traditional operations. In order to exchange the information, the system utilizes highly sophisticated networked devices that will perform a variety of tasks. These devices (a.k.a as things) cooperate, share information and act as part of communities. These devices comprises of computing elements having communication and sensing capabilities. They may be able to realize a common task by cooperating among each other. Therefore, these things must have computation, communication and sensing facility. This cooperation can be application specific in many cases; however, there can be a shared abstraction in case of heterogeneous devices [19]. Thus the task of these things in context of smart grid falls under the umbrella of networked embedded systems, wireless sensor networks and ubiquitous computing. Example architecture for IoT enabled network is depicted in Fig. 2. In this architecture, things such as sensors and actuators provide feedback to the micro grid as shown in Fig. 1. Here, the cloud system is used to provide the processing and storage capabilities. Although IoT and cloud have seen an independent evolution their mutual advantages are extremely beneficial for the smart grid. The following advantages are achieved by using the Cloud with IoT paradigm.

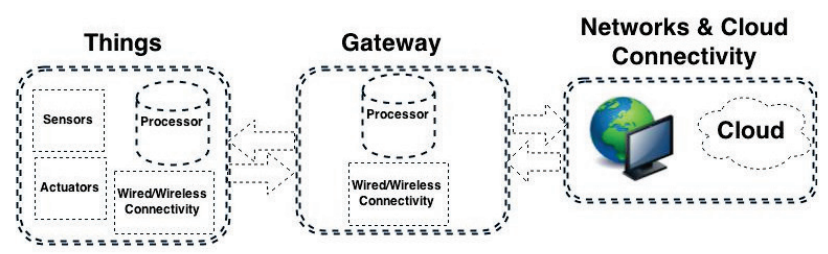

Figure 2 Architecture for loT enabled network

\subsubsection{Processing and Computation}

The IoT enabled devices possess very limited processing and computational resources. Normally the collected data is transmitted to high capacity nodes that are capable of aggregating and processing the data. However, that model may fail due to scalability issues when a large number of IoT enabled devices are transmitting the data.
The higher processing capabilities of cloud ensure that the processing and computation needs are fulfilled with minimum delay. In Fig. 2 the data from the devices is transmitted to Gateway, which is relatively a high power node. In case the gateway is not able to perform the necessary computation, the data is forwarded to the cloud. The cloud connectivity can provide the data driven decision making and prediction algorithms. Thus it is possible to perform the real-time processing, management of complex events and implement task offloading for saving the energy.

\subsubsection{Storage Resources}

The IoT is composed of a large number of devices (things) which act as information sources. These information sources generate a huge amount of data. The data generated by IoT has the characteristics of big data. These three characteristics are Volume, Velocity and Variety. This means that there is large amount of data (Volume) having huge diversity (Variety) and extremely quick generation frequency (Velocity). As a consequence, the IoT system has to deal with collecting, archiving, accessing, storing and sharing a huge amount of data. The cloud provides the most convenient system having low cost and on-demand storage. The cloud ensures that data is treated as homogenous, secure and accessible from any place.

Apart from storage and processing, the cloud can provide new paradigm for IoT enabled network. Sensing as a Service (SaaS) provides the ubiquitous access to the sensor data. Sensing and Actuation as a Service (SAaaS) enabled the automatic control logics implemented in the cloud [20]. Similarly, SEaaS (sensor Event as a Service) is used for messaging services prompted by sensor events [21].

\subsubsection{Micro-grid Based Energy Optimization}

A micro-grid smart grid system is considered and the homes of the considered locality are connected to the system via an IoT based network. There are a few RE generation sources present in the system and the main task of the micro-grid system is to ensure usage of these sources instead of the power supplied by the energy company.

In order to minimize the cost, the supply requirement for a locality needs to be provided. This problem can be solved at customer premises or at the micro-grid level. The micro-grid is connected to devices through IoT network and each device can provide the knowledge of power requirement that will be used to it for minimizing the usage of supply taken from the outside sources.

\subsubsection{Problem Formulation}

The devices are scheduled in order to achieve the following objectives:

$$
P_{\text {Required }} \leq P_{\text {RenewableEnergy }}
$$

Having constraints:

$$
P_{\text {Wind }} \leq P_{\text {Wind-Limit }}
$$




$$
P_{\text {Photovoltaic }} \leq P_{\text {Photovoltaic-Limit }}
$$

Here, the goal is to use locally generated RE in order to make a greener community. In the first step, the devices are scheduled by considering their priorities. In the next step, the peak value for power consumption is minimized by considering the devices' priorities. In an IoT network, the devices can communicate directly with the micro-grid and update their power consumption requirements. Two cases are going to be considered; in the first one, each device makes its own decision to use the power while in the second case, each device is given a schedule by the micro-grid to minimize the use of electricity supplied by the energy company. The scheduling time is:

$$
t_{s} \in T:=\{1,2,3, \ldots, T\}
$$

where $T=24$ hours for a day.

Total Household appliances: $=\{$ Delay Tolerable Appliances + Delay Intolerable Appliances $\}$ [8]

where Delay Tolerable Appliances (DTA): = Timed Appliances and Regular Appliances

where Timed Appliances (TAs) have specific deadline for operation completion while regular Appliances use internal control system such as thermostat.

$$
d_{a} \in D T A:=\left\{d_{a 1}, d_{a 2}, \ldots, d_{a n}\right\}
$$

where $n=$ number of delayable appliances

$d_{a}=$ Any specific delayable appliance from the set of DTA

The total power required for each $d_{a}$ to complete its operation is:

$$
P_{d a}:=\left\{P_{d a 1}, P_{d a 2}, \ldots, P_{d a n}\right\}
$$

and per unit time power consumption of each $d_{a}$ is given as follows:

$$
\begin{gathered}
X_{d a}:=\left\{X_{d a 1}, X_{d a 2}, \ldots, X_{d a n}\right\} \\
t_{s}:=\left\{P_{s 1}, P_{s 2}, \ldots, P_{s n}\right\}
\end{gathered}
$$

Constraints:

$$
t_{s} \in\left[T_{L}, L S T\right]
$$

where: $L S T=$ latest start time for TAs from which operation of TAs must be started and it can be obtained by subtracting the length of appliance operation from their upper time limit $\left(T_{U}\right)$ and $L S T=T U-l_{d a i}$.

\subsubsection{Analysis}

For the sake of theoretical analysis, 10 houses have been assumed to be connected to the micro-grid. The analysis has been performed by considering the average power consumption of Regular and Timed appliances as these are the most common household devices. While actual power consumption of timed appliances is considered and these devices are the focus of the analysis as they can be scheduled during a specified time period. Tabs. 1, 2 and 3 describe the specification of timed devices, regular devices and non-delayable devices respectively.
The available energy pricing is given in Tab. 4. Nevertheless, the price for the renewable energy (RE) source is comparable to that supplied by the main grid. However, the objective is to minimize the use of nonrenewable energy sources as it is greener for the environment. The algorithm for achieving the mentioned objectives is described in Algorithm 1. The algorithm makes sure that all the devices present in the locality are given a schedule for operation in order to minimize taking energy from external sources. To the best of our knowledge, such a task has not been found in literature. Therefore, the results of the proposed algorithm are compared with the situation where each device makes an individual greedy decision to begin its operation. The results have been described in Figs. 3 and 4 and they show that by using the proposed algorithm, the average power required during an hour decreases and the use of renewable energy can be increased. As we have got a limited RE sources, the Figure describes how much gain will be attained based on available RE sources. This source can also fluctuate during the course of a day. Finally, Fig. 5 shows the extra energy required per day given an upper bound on the production of RE. For example, the electric energy generated from Photovoltaic is going to reduce during cloudy days while it is going to increase during sunny days. As per the analysis for the considered case, if $\mathrm{RE}$ limit is more than $30 \mathrm{~kW}$, then the proposed algorithm will significantly reduce the power purchase budget and it will result in a greener environment.

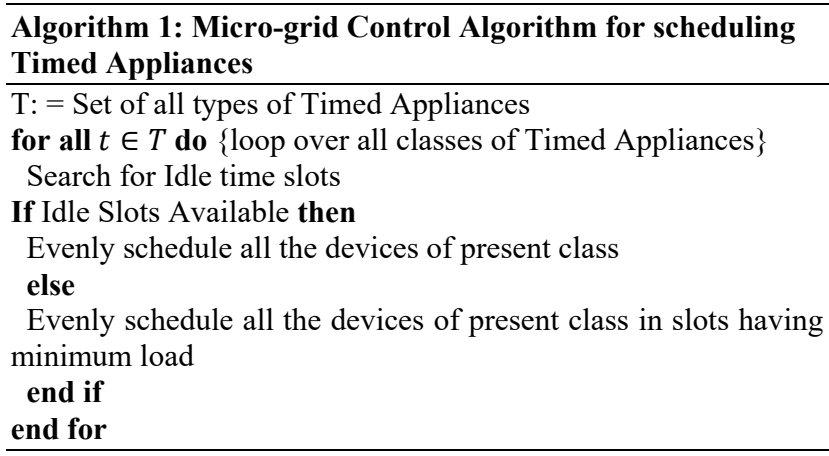

Table 1 Specifications of regular appliances [8]

\begin{tabular}{|l|c|c|c|c|}
\hline \multicolumn{1}{|c|}{ Appliance } & $\begin{array}{c}\text { Power } \\
(\mathrm{kW})\end{array}$ & $\begin{array}{c}\text { Lower time } \\
\text { limit }\left(T_{L}\right)\end{array}$ & $\begin{array}{c}\text { Upper time } \\
\text { limit }\left(T_{U}\right)\end{array}$ & Priority \\
\hline Air conditioner & 1.44 & 6 & 24 & 1 \\
\hline Refrigerator & 0.725 & 6 & 24 & 2 \\
\hline Water heater & 4.45 & 6 & 24 & 3 \\
\hline Space heater & 1.5 & 6 & 24 & 4 \\
\hline
\end{tabular}

Table 2 Specifications of non-delayable appliances [8]

\begin{tabular}{|l|c|}
\hline \multicolumn{1}{|c|}{ Appliance } & Power $(\mathrm{kW})$ \\
\hline Lighting & 0.06 \\
\hline Entertainment & 0.15 \\
\hline Fans & 0.75 \\
\hline Cloths iron & 1.5 \\
\hline Microwave oven & 1.18 \\
\hline Toaster & 0.05 \\
\hline Laptop charger & 0.05 \\
\hline
\end{tabular}


Table 3 Specifications of timed appliances [8]

\begin{tabular}{|c|c|c|c|c|c|}
\hline Appliance & Power $(\mathrm{kW})$ & $\begin{array}{c}\text { Lower time } \\
\text { limit }\left(T_{L}\right)\end{array}$ & $\begin{array}{c}\text { Upper time limit } \\
\left(T_{U}\right)\end{array}$ & $\begin{array}{c}\text { Length of operation } \\
\text { cycle }\left(l_{\text {dai }}(h)\right)\end{array}$ & $\begin{array}{c}\text { Waiting time of } \\
\text { appliances }\left(W T A_{\max }\right)\end{array}$ \\
\hline Washing machine & 0.78 & 8 & 16 & 1 & 7 \\
\hline Dish washer & 3.6 & 7 & 12 & 1 & 4 \\
\hline Cloth dryer & 4.4 & 6 & 18 & 2 & 10 \\
\hline Plug-in hybrid electric vehicle (PHEV) & 3.6 & 18 & 24 & 33 & \\
\hline
\end{tabular}

Table 4 Available energy price [10]

\begin{tabular}{|l|c|}
\hline \multicolumn{1}{|c|}{ Source } & Price (EUR/kWh) \\
\hline Wind & 0.4 \\
\hline Photovoltaic & 0.4 \\
\hline Fuel Cell & 0.9 \\
\hline Storage Discharging & 0.6 \\
\hline Storage Charging & 0.4 \\
\hline Electricity & 0.4 \\
\hline
\end{tabular}

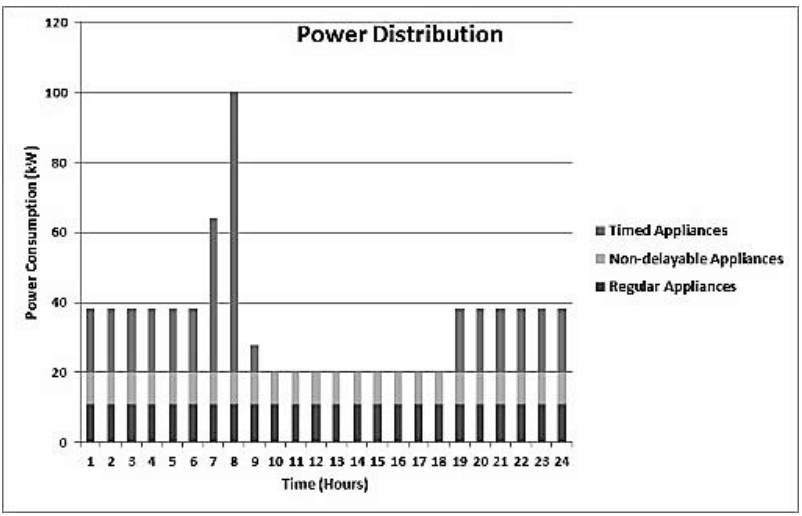

Figure 3 Power distribution without micro-grid

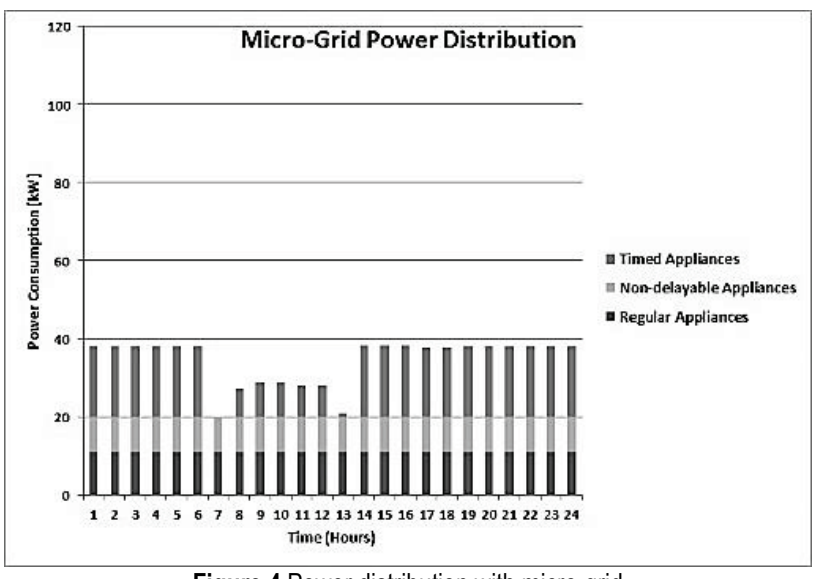

Figure 4 Power distribution with micro-grid

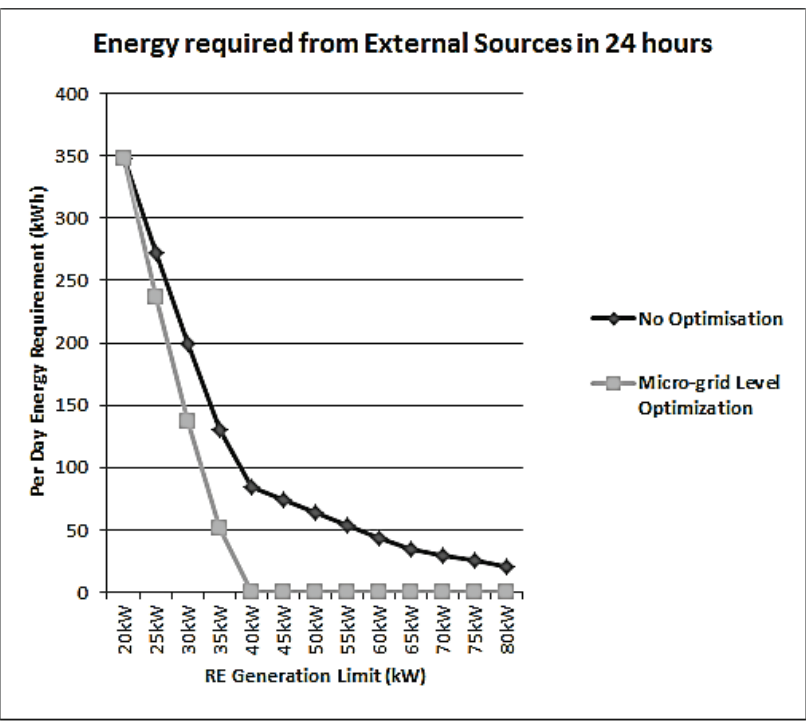

Figure 5 External sources energy required per day

\section{CASE STUDY FOR A ROBOTICS APPLICATION}

The proposed solution can also be applied to a network consisting of robots that needs to be charged. In order to discuss such a possibility, the discussion is done by considering different types of robotic applications in this section.

\subsection{Industrial Robots}

These robots are used in the manufacturing area for applications such as welding, painting, material handling, etc. They have got their own power consumption profile and based on a proper schedule, the use of RE in industrial sectors can be enhanced.

\subsection{Domestic or household robots}

These robots are used in household applications such as vacuum cleaning, sweeping, gutter cleaning, surveillance. Each type of application has its own power requirement that can be satisfied by using locally generated $\mathrm{RE}$ in conjunction with the IoT and microgrid.

\subsection{Medical Robots}

In such applications, the robots are used for application in medical institutions such as surgery, material handling, etc. The proposed solution can also help the medical institute to use the greener form of energy.

\section{CONCLUSION}

In this article, we proposed architecture for optimizing the energy resources and cost by collecting the information and performing optimal decisions on that information. The proposed architecture utilizes different energy sources efficiently and allocates the energy to the devices according to their demand and importance. Moreover, the microgrid is integrated with IoT enabled network for collecting the feedback in a uniform manner. The IoT enabled network collects the data from different devices. Due to huge data size and high computation, the services of cloud is used to store the data and perform the required computation efficiently with minimum delay. Finally, the analysis of the proposed architecture shows the significant reduction in cost due to decreased usage of electricity from power supply. As a future work, the proposed architecture can be deployed on real life applications for realizing the proposed objectives.

\section{REFERENCES}

[1] Prez-Lombard, L., Ortiz, J., \& Pout, C. (2008). A review on buildings energy consumption information. Energy and Buildings, 40(3), 394-398.

https://doi.org/10.1016/j.enbuild.2007.03.007 
[2] Javed, F. \& Arshad, N. (April 2009). A penny saved is a penny earned: Applying optimization techniques to power management. The $16^{\text {th }}$ Annual IEEE International Conference and Workshop on the Engineering of Computer Based Systems, ECBS 2009, 128-137.

[3] Das, A. \& Balakrishnan, V. (April 2010). Energy service companies (escos) to optimize power in peak demand period in hybrid energy system: An impact on climate change. IEEE Green Technologies Conference, 1-10. https://doi.org/10.1109/GREEN.2010.5453792

[4] Molderink, A., Bakker, V., Bosman, M., Hurink, J., \& Smit, G. (2010). Management and control of domestic smart grid technology. IEEE Transactions on Smart Grid, 1(2), 109119. https://doi.org/10.1109/TSG.2010.2055904

[5] Nygard, K., Ghosn, S., Chowdhury, M., Loegering, D., McCulloch, R., \& Ranganathan, P. (2011). Optimization models for energy reallocation in a smart grid. IEEE Conference on Computer Communications Workshops (INFOCOM WKSHPS), April, 186-190. https://doi.org/10.1109/INFCOMW.2011.5928804

[6] Kostevek, A., Cizelj, L., Petek, J., \& Pivec, A. (2013). A novel concept for a renewable network within municipal energy systems. Renewable Energy, 60(0), 79-87. https://doi.org/10.1016/j.renene.2013.04.013

[7] Hassanzadeh, A. (2012). Design and optimization of closedloop supply chain management. PhD dissertation. Department of Industrial and Manufacturing Systems Engineering, University of Winsdor, Winsdor, Ontario, Canada.

[8] Khan, M. A., Javaid, N., Mahmood, A., Khan, Z. A., \& Alrajeh, N. (2015). A generic demand-side management model for smart grid. International Journal of Energy Research, 39(7), 954-964. https://doi.org/10.1002/er.3304

[9] Provata, E., Kolokotsa, D., Papantoniou, S., Pietrini, M., Giovannelli, A., \& Romiti, G. (2015). Development of optimization algorithms for the leaf community microgrid. Renewable Energy, 74(0), 782-795. https://doi.org/10.1016/j.renene.2014.08.080

[10] Morais, H., Kdr, P., Faria, P., Vale, Z. A., \& Khodr, H. (2010). Optimal scheduling of a renewable micro-grid in an isolated load area using mixed-integer linear programming. Renewable Energy, 35(1), 151-156. https://doi.org/10.1016/j.renene.2009.02.031

[11] ul Haq, M. A., Hassan, M. Y., Abdullah, H., Rahman, H. A., Abdullah, M. P., Hussin, F., \& Said, D. M. (2014). A review on lighting control technologies in commercial buildings, their performance and affecting factors. Renewable and Sustainable Energy Reviews, 33(0), 268-279. https://doi.org/10.1016/j.rser.2014.01.090

[12] Aslam, W., Soban, M., Akhtar, F., \& Zaffar, N. A. (2015) Smart meters for industrial energy conservation and efficiency optimization in Pakistan: Scope, technology and applications. Renewable and Sustainable Energy Reviews, 44(0), 933-943. https://doi.org/10.1016/j.rser.2015.01.004

[13] Zhou, K., Yang, S., Chen, Z., \& Ding, S. (2014). Optimal load distribution model of microgrid in the smart grid environment. Renewable and Sustainable Energy Reviews, 35(0), 304-310. https://doi.org/10.1016/j.rser.2014.04.028

[14] Bjelic, I. B. \& Ciric, R. M. (2014). Optimal distributed generation planning at a local level a review of Serbian renewable energy development. Renewable and Sustainable Energy Reviews, 39(0), 79-86. https://doi.org/10.1016/j.rser.2014.07.088

[15] Cong, R.-G. (2013). An optimization model for renewable energy generation and its application in china: A perspective of maximum utilization. Renewable and Sustainable Energy Reviews, 17(0), 94-103.

https://doi.org/10.1016/j.rser.2012.09.005
[16] Chang, C.-T. (2015). Multi-choice goal programming model for the optimal location of renewable energy facilities. Renewable and Sustainable Energy Reviews, 41(0), 379-389. https://doi.org/10.1016/j.rser.2014.08.055

[17] Khan, Z. A. \& Faheem, Y. (2014). Cognitive radio sensor networks: Smart communication for smart grids - a case study of Pakistan. Renewable and Sustainable Energy Reviews, 40(0), 463-474. https://doi.org/10.1016/j.rser.2014.07.144

[18] Kehoe, B., Patil, S., Abbeel, P., \& Goldberg, K. (2015). A survey of research on cloud robotics and automation. IEEE Transactions on Automation Science and Engineering, 12(2), 398-409. https://doi.org/10.1109/TASE.2014.2376492

[19] Marron, S. K. P. J., \& Minder, D. (2009). Research roadmap on cooperating objects. European Commission, Office for Official Publications of the European Communities.

[20] Rao, B., Saluia, P., Sharma, N., Mittal, A., \& Sharma, S. (2012). Cloud computing for internet of things amp; sensing based applications. Sixth International Conference on Sensing Technology (ICST 2012), 374-380. https://doi.org/10.1109/ICSensT.2012.6461705

[21] Zaslavsky, A. B., Perera, C., \& Georgakopoulos, D. (2013). Sensing as a service and big data. CoRR, vol. abs/1301.0159.

Contact information:

Zeeshan ALI KHAN

Department of Electrical Engineering,

Riphah College of Science and Technology (RCST),

Riphah International University, Lahore, Pakistan

zeeshan.alikhan@riphah.edu.pk

Ubaid ABBASI, Assistant Professor

Computer Science Department,

GPRC, Grand Priaire,

$\mathrm{AB}$, Canada

UAbbasi@gprc.ab.ca

$+1-4389236182$ 